\title{
The Role of Digital Transformation of Industrial Enterprises in the Innovative Development of the Region
}

\author{
Natalia S. Khoroshavina $1 *$ [ORCID 0000-0002-6563-2047], \\ Viktoriya E. Barkovskaya 1[ORCID 0000-0002-5823-354X], \\ Olga P. Ivanova 2[ORCID 0000-0002-9563-4166]
}

\author{
${ }^{1}$ LEONOV Moscow Region University of Technology, Korolev, Russia \\ ${ }^{2}$ Yaroslav-the-Wise Novgorod State University, Veliky Novgorod, Russia \\ nataxoroshavina@mail.ru
}

\begin{abstract}
The growth of the country's innovative potential is impossible without the innovative development of its territories. It is the regional innovative development that determines the innovative path of the state, ensures its competitiveness and helps to strengthen its position in the world market. At the same time, industrial enterprises play a decisive role in the activities of the region, which not only affect the socio-economic indicators of the region, but also ensure its innovative development. Industrial enterprises produce innovative products, promote the introduction of innovations, create high-tech jobs, which affects the innovative potential of the region and its innovative activities. Thanks to industrial enterprises, a favorable innovation climate is being formed in the region. At the same time, in modern conditions, the development of industrial enterprises can only be ensured through digital transformations. Digitalization is becoming an integral part of the business processes of industrial structures and determines their innovative focus. It is the digital transformation of industrial enterprises that should form the basis of regional innovative development. The article is devoted to the study of the role of digital transformation of industrial enterprises in the innovative development of the region. In the study, based on the identified approaches to the definition of the concept of "digital transformation", the author's interpretation of "digital transformation of industrial enterprises" is proposed. Based on the analysis of the indices of innovative development of regions and the level of digitalization of industrial enterprises, the influence of the latter on regional innovative development is determined. The methodological apparatus used in the study, which includes methods of economic analysis, statistical generalizations and groupings, graphic presentation of the material, made it possible to identify the relationship between the digital transformation of industrial enterprises and indicators of the innovative development of the region, on the basis of which the authors substantiated the need to develop a strategy for creating conditions for digital transformation industrial enterprises of the region, based on indicators of regional innovative development and taking into account the specifics of its production sphere. The conclusions obtained in the course of the study have a scientific and practical orientation and can be used in the formation of digital transformation strategies by regions.
\end{abstract}

Keywords: digital transformation, industrial enterprises, innovative development of the region

\section{INTRODUCTION}

Industrial enterprises play a leading role in the innovative development of the region. It is industrial enterprises that ensure the achievement of key indicators of regional innovative development. Industrial enterprises manufacture innovative products, develop and introduce innovations into production, create high-tech jobs, increasing the innovative potential of the region's human capital.

In modern conditions of digital transformations, further innovative development of both industrial enterprises themselves and the region as a whole is 
impossible without the introduction and use of digital technologies in the production process. The use of digital technologies at industrial enterprises in the region should not be of a single point, but of an integrated, systemic nature. On the one hand, it is necessary to restructure the business processes of an industrial enterprise into a digital channel, on the other, to ensure the required level of digitalization in the external environment, i.e. at the regional level, create a digital space in which industrial enterprises will play a leading role.

Leading domestic experts have long been engaged in the issues of innovative development of the region. To date, models have been developed (I.Ya. Buyakova, O.M. Mikhaleva) [1], principles (V.G. Belomestnov) [2] of regional innovative development, directions of development of the region (I.L. Kaverzin) [3]. The issues of digital transformation of industrial enterprises are touched upon in the works of such authors as S.S. Golubev, M.Ya. Veselovsky, G.I. Andryushenko [4], M.A. Izmailova, L.A. Yunusov, I.A. Yunusov [5], M. Getz, B. Yankovskaya [6], T.A. Lezina, A.A. Saltan [7] and others. Problems of digitalization of business structures are reflected in the works of such authors as E.D. Burda, I.O. Volkova, E.V. Gavrikova, A.V. Kosigina [8], O.S. Savish, D.D. Burkaltseva, I.V. Kuryanova, D.V. Nekhaichuka, A.A. Stepanova, A.S. Tyulina, Sh.U. Niyazbekova [9], T.A. Tyuleneva [10] and others. Problems of digitalization of the economy at the regional level are considered by V.A. Savinova, E.V. Zhegalova, E.V. Semernina, A.S. Kozlova [11] and others.

At the same time, today, insufficient attention has been paid to the issues of the impact of digital transformation of industrial enterprises on regional innovative development. In this regard, there is a need to study the relationship between digital transformations in industry and the level of innovative development of the region.

Within the framework of this work, a hypothesis is put forward that the digital transformation of industrial enterprises provides an increase in the main indicators of regional innovative development.

\section{MATERIALS AND METHODS}

The purpose of this scientific work is to study the impact of digital transformation of industrial enterprises on regional innovative development.

The implementation of this goal will be ensured through the implementation of the following tasks:
1) define the essence of the concept of "digital transformation of industrial enterprises";

2) to analyze the level of innovative development of the regions of the Russian Federation, based on an assessment of the innovative development index and its components;

3) assess the level of digitalization of industrial enterprises;

4) determine the factors of digital transformation of industrial enterprises that have the greatest impact on the innovative development of the region.

The methodological apparatus of the research is based on the use of methods of economic analysis, statistical generalizations and groupings, graphic presentation of the material.

The empirical basis for this study was the research materials carried out by the National Research University Higher School of Economics (hereinafter - NRU HSE), as well as official statistics from the Federal State Statistics Service, the Ministry of Industry and Trade of the Russian Federation.

\section{RESULTS}

The innovative development of the regions determines the innovative path of the country. It is the regions that ensure technological progress and, accordingly, the country's prosperity, and have a significant impact on global innovation trends. The socio-economic situation of the country and its competitiveness in the world market depend on the level of regional innovative development. In this regard, an important role in the economic policy of the state is given to the provision of measures for the uniform innovative development of their regions.

At the same time, according to the rating of innovative development of the constituent entities of the Russian Federation presented by the NRU HSE, there are still significant interregional differences in the innovation sphere on the territory of the country [12].

The highest level of development is observed in six regions. At the same time, the leader is Moscow, and the Moscow region closes the top six. The lowest level of development is observed in eight regions, mainly located in the North Caucasian Federal District.

It is also important to note the innovative 
difference between the regions in terms of individual rating indicators. Thus, the most favorable socioeconomic conditions for innovative activity are observed in Moscow, the Yamalo-Nenets Autonomous Okrug, St. Petersburg, the Republic of Tatarstan and the Tomsk region. The Tomsk, Ulyanovsk, Tyumen, Nizhny Novgorod regions and St. Petersburg have the greatest scientific and technical potential. The Chuvash Republic, Moscow, St. Petersburg are the leaders in the Innovative Activity sub-index, and St. Petersburg, the Primorsky Territory and the Tula Region are the leaders in the Export Activity sub-index. At the same time, the highest quality innovation policy is observed in such regions as the Republic of Tatarstan, Moscow and the Moscow region [12].

Uneven development of individual components of the regional innovation index, ultimately, is reflected in the general level of innovative development of the region. Thus, the YamaloNenets Autonomous Okrug, having the most favorable socio-economic conditions for innovative activity (2nd position in the rating for this subindex), takes only 61 positions in terms of the level of innovative development. This situation is influenced by the low quality of innovation policy (83rd place), as well as insufficiently high export activity and innovation activity (66th and 65th positions in the rating, respectively).

An important factor determining the level of innovative development of the region is the digital transformation of its industrial enterprises. Digital transformation is ubiquitous today. They affect all areas of activity, penetrate into all areas of the economy. Industrial enterprises, playing a leading role in the innovative development of the region, must first of all be subjected to digital transformation.

Today there is no single approach to the definition of the concept of "digital transformation". The ambiguity of its interpretation is determined, first of all, by the specifics of the research object (economy, enterprise, region, industry, etc.). But even within the framework of one object, you can see different approaches to the definition of the concept of "digital transformation". This paper deals with the digital transformation of industrial enterprises, i.e. business structures. In this regard, it is necessary to establish the existing approaches to the definition of the concept of "digital transformation of the enterprise".

Thus, according to HSE specialists, the digital transformation of an enterprise is "qualitative changes in business processes or ways of carrying out economic activities (business models) as a result of the introduction of digital technologies, leading to significant socio-economic effects" [13].

The head of the project "Digital Economy of the Russian Federation" V. Mesropyan gives the following definition of the concept of "digital transformation of an enterprise" - it is "revolutionary changes in business models based on the use of digital platforms, which lead to a radical increase in market volumes and the competitiveness of companies" [4].

Within the framework of this work, digital transformation of industrial enterprises will mean the transition of production and other business processes of industrial enterprises from traditional forms of doing business to digital, which ensures an increase in the main indicators of the enterprise and contributes to its innovative development. The digital transformation of industrial enterprises, based on the use of advanced innovative digital technologies, will become a catalyst for the innovative development of not only the enterprise itself, but also the region as a whole. It will help improve the quality of goods, reduce costs and increase the level of competitiveness of industrial enterprises.

Moreover, in accordance with the developed by the Ministry of Industry and Trade of the Russian Federation "Strategy of Digital Transformation of Manufacturing Industries" in Order to Achieve their "Digital Maturity" until 2024 and for the Period up to 2030", the digital transformation of industrial enterprises will take place through the introduction and use of innovations in the organization of production, in the field of personnel management, in the field public administration, as well as through the implementation of product and technological innovations.

Realizing the importance of digital transformation, many industrial enterprises are already actively introducing digital technologies into the production process. According to a study by the National Research University Higher School of Economics in 2020, more than $70 \%$ of the surveyed enterprises have already implemented digital technologies, and the rest are planning to implement them within the next five years [14].

Large industrial enterprises of the extractive industry in various regions of the country have their own digital transformation strategies. Thus, in 2019, the Gazprom (PJSC) Board of Directors approved 
the Digital Transformation Strategy based on the use of a set of major programs of changes in technological and operational processes in order to achieve key economic and business effects. The implementation of this strategy allowed the company to introduce a product approach already in 2020 within the framework of such programs as "Asset of the Future", "Talent Management", "Production Control Center (Oil Refining)".

The state-owned company Zarubezhneft JSC (AO) became one of the first enterprises in the mining industry that approved the digital transformation strategy. The approved strategy provides for the use of machine learning technology, big data processing, "digital twins" and artificial intelligence. According to a preliminary estimate of the company's experts, the volume of additional income and cost reduction due to the implementation of the digital transformation strategy will amount to 2 billion rubles [15].

Digital transformation is actively taking place in the manufacturing sector, which is the leader in digitalization among other industries. The manufacturing industry continues to show an increase in digital activity, according to a market research study by the Higher School of Economics (Figure 1).

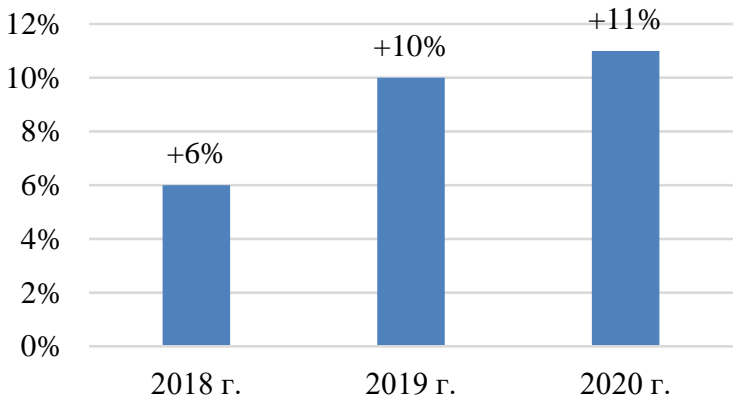

Figure 1. Dynamics of the balance of the level of digital activity

Source: [16]

As you can see from Figure 1, for 2019 and 2020 , there is an increase in the balance of the level of digital activity of manufacturing enterprises. At the same time, the balance is understood as the difference in the shares of respondents in the surveyed period, who noted the "increase" and "decrease" in the indicator in comparison with the previous period. Thus, in 2019, industrial enterprises that noted an increase in digital activity were $10 \%$ more than enterprises that noted a decrease, and in 2020 the value of this indicator increased by 1 percentage point. and amounted to $11 \%$. The largest increase in digital activity in 2020 was observed in the furniture industry and amounted to $40 \%$ [17].

At the same time, the balance of demand for digital technologies in 2020 is decreasing compared to 2019 (Figure 2). At the same time, the greatest demand for digital technologies is typical for the pharmaceutical, oil refining and leather industries.

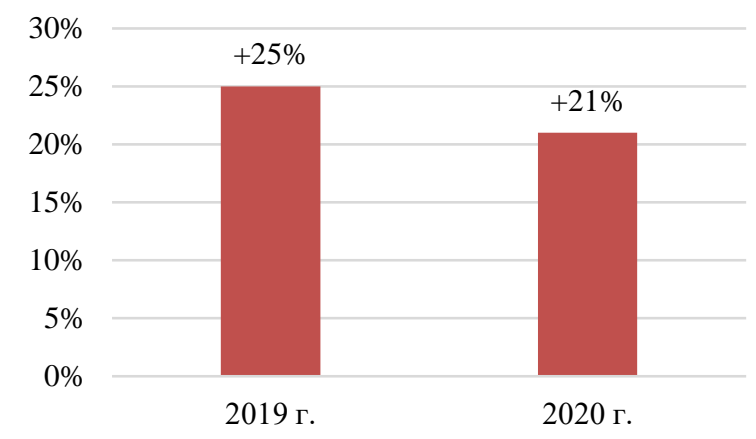

Figure 2. Trends in digital demand

Source: [17]

According to the National Research University Higher School of Economics, the most significant digital technologies for industrial enterprises are still industrial robots, artificial intelligence and machine learning (Figure 3).

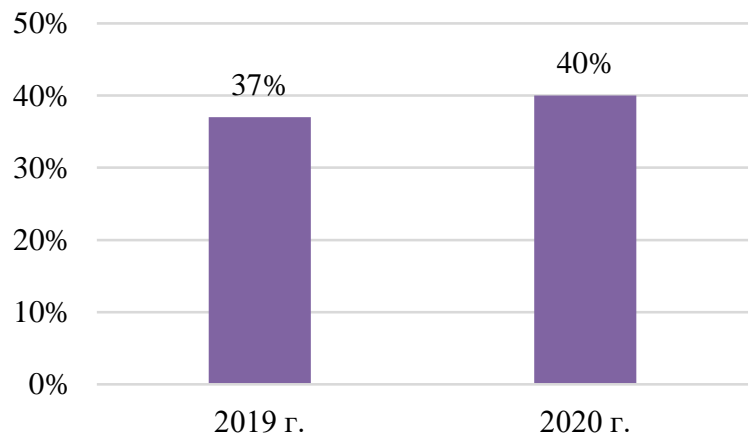

Figure 3. Digital Significance Index for industrial enterprises in 2020

Source: [18]

At the same time, the priority of using certain digital technologies is determined, first of all, by the industry affiliation of the enterprise. Thus, robotization and automation of production control systems, as well as the use of machine vision technology, have found the greatest application in metallurgy, mechanical engineering and the oil and gas sector.

On the negative side, the growth in 2020 of manufacturing enterprises with low adaptability to digital technologies should be noted (Figure 4).

At the same time, the worst dynamics is noted in the production of electrical equipment, rubber and 
plastic products, as well as textiles.

However, the digital transformation of industrial plants is gaining momentum. More and more large Russian manufacturers, to one degree or another, base their business processes on the use of digital technologies. At the same time, digital transformation affects not only the industrial enterprise itself, but invariably affects all elements of the region's ecosystem, ensuring its innovative development.

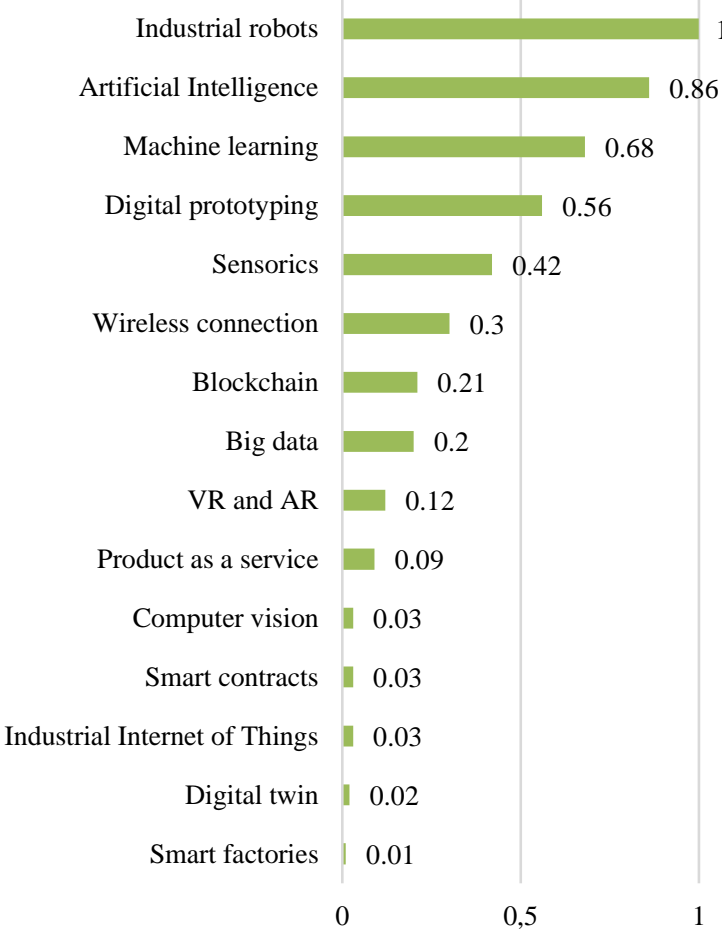

Figure 4. Share of industrial enterprises with low adaptability to digital transformation

Source: [17]

First, the digital transformation of industrial enterprises contributes to an increase in the volume of production of high-tech products, which affects the improvement of the innovation performance index of the region.

Secondly, a reduction in the cost of servicing high-tech products is ensured, which allows enterprises in the region to actively use them in their activities. This, in turn, contributes to an increase in activity in the field of technological and nontechnological innovations, which also affects the index of innovative activity in the region.

Thirdly, the digital transformation of industrial enterprises increases the return on assets through the use of modern technological equipment and the use of cooperative chains, and also reduces the payback period for investments in innovative developments. Accordingly, the investment activity of regional business structures is increasing, which ensures an increase in the index of the innovative potential of the region.

Fourth, thanks to the digital transformation of industrial enterprises, the region receives highly qualified personnel with digital competencies and capable of working in a digital economy. Thus, there is an increase in the quality of the region's human capital, an increase in its innovative potential, which is also reflected in the index of the region's innovative potential.

Thus, the digital transformation of industrial enterprises has a significant impact on the innovative development of the region. At the same time, effective digital transformation can only be achieved through the development and implementation of an appropriate strategy both at the level of industrial structures and at the regional level. Already today, many regions have presented their digital transformation strategies, in which, in addition to mandatory sectors of the economy and social sphere, such as public administration, healthcare, education and science, transport and urban economy, directions of digital transformations in the field of industry are included. These include, in particular, the standardization of smart production technology, the certification of virtual tests, the formation of a digital passport for industrial enterprises, etc.

In our opinion, this is not enough. A separate strategy should be worked out to create the conditions necessary for the digital transformation of industrial enterprises in the region, based on indicators of regional innovative development and taking into account the specific features of regional production systems. At the same time, the basis of the regional strategy should be the digital transformation strategy of the manufacturing industries, developed by the Ministry of Industry and Trade. A detailed strategy for the digital transformation of the region's industry will allow to smooth out existing risks, level threats and most effectively use the opportunities of a particular region for industrial enterprises. This, in turn, will become the basis for increasing the level of innovative development of the region, and, consequently, will ensure its sustainable socioeconomic position. In addition, the strategy will make it possible to smooth out the differences between regions in terms of the level of innovative development, which will affect the country's position in the world market. 


\section{DISCUSSION}

The digital economy has already become an integral part of our lives. Digitalization is increasingly penetrating all areas of activity. Digital technologies are actively used in public administration, in education and healthcare, in the activities of many enterprises, including industrial ones. Moreover, it is industrial enterprises that determine the socio-economic and innovative development of the region. Industry is the foundation for the development and implementation of innovations. High-tech jobs are being created at industrial enterprises. It is industry that provides a significant investment in $R \& D$. In this regard, the digital transformation of industrial enterprises is a determining factor in the innovative development of the region. Without digital transformation, industry will not be able to compete in the global market. At the same time, digital transformation is based on the use of modern information innovative technologies.

Thus, the study made it possible to draw a number of important conclusions:

1) the decisive role in the innovative development of the region is played by the digital transformation of industrial enterprises;

2) digital transformations in industry are influenced by changes in the sub-indices of regional innovative development;

3) the regions need a strategy for digital transformation of industry, based on a strategy, based on the strategy of the Ministry of Industry and Trade and taking into account not only the specifics of the region's industry, but also indicators of its innovative development.

\section{CONSLUSION}

As a result of the study, the hypothesis put forward about the impact of the digital transformation of industrial enterprises in the region on the main indicators of regional innovative development has been confirmed. The factors of digital transformation are identified that most significantly affect the improvement of the subindices of innovative development of the region, such as innovation and innovation potential.

The relationship between the digital transformation of industrial enterprises and the innovative development of the region, revealed in the course of the study, can in practice be used as the basis for developing a strategy for the digital transformation of regional industrial enterprises.

Further research can be aimed at developing a mechanism for implementing a digital transformation strategy for industrial enterprises in the region.

\section{AUTHORS' CONTRIBUTIONS}

Natalia S. Khoroshavina, Olga P. Ivanova: general project management, analysis and addition of the text. Viktoriya E. Barkovskaya: collection and processing of materials, preparation of the initial version of the text.

\section{REFERENCES}

[1] I.A. Buyakova, O.M. Mikhaleva, "An Innovative Model of Regional Development", Bulletin of BSU, 2012 vol. 3(1), pp. 92-95. (In Russ.).

[2] V.G. Belomestnov, "Principles of Innovative Development of the Region", Bulletin of BSU, 2011, vol. 2, pp. 60-62. (In Russ.).

[3] I.L. Kaverzin, "Directions of innovative development of the region", Modern Competition, 2011, vol. 4, pp. 120-124. (In Russ.).

[4] S.S. Golubev, M.Y. Veselovsky, G.I. Andryuschenko, I.V. Balynin, "Quality transformation of high technology industrial enterprises corporative management in terms of transition to digital technology", Quality Access to Success, 2020, vol. 21(176), pp. 3-8.

[5] M.Y. Veselovsky, M.A. Izmailova, L.A. Yunusov, I.A. Yunusov, "Quality of digital transformation management on the way of formation of innovative economy of Russia", Quality - Access to Success, 2019, vol. 20(169), pp. 66-71.

[6] M. Götz, B. Jankowska. “Adoption of Industry 4.0 Technologies and Company Competitiveness: Case Studies from a PostTransition Economy", Foresight, 2020, vol. 4, pp. 61-78.

[7] V. Nissen, T. Lezina, A. Saltan, "The Role of IT-Management in the Digital Transformation of Russian Companies”, Foresight, 2018, vol. 3, pp. 53-61.

[8] Y.D. Burda, I.O. Volkova, E.V. Gavrikova, 
A.V. Kosygina, "Digitalization and Ways for the Development of the Electric Energy Industry with the Participation of Consumers: New Challenges for Shaping the Investment Climate", Journal of SibFU. Humanities and Social Sciences, 2019, vol. 4, pp. 545-564. DOI: $10.17516 / 1997-1370-0408$

[9] O.S. Sivash, D.D. Burkaltseva, I.V. Kuryanova, D.V. Nekhaychuk, A.A. Stepanov, A.S. Tyulin, Sh. Niyazbekova, "Trends and consequences of introduction of automation and digitalization of enterprises, industry, and economy", Revista Inclusiones, 2020, vol. 7(S2-3), pp. 15-31.

[10]T.A. Tyuleneva, "Problems and Prospects of Regional Mining Industry Digitalization", in Proceedings of the E3S Web of Conferences: 5, Kemerovo, 2020.2 DOI: $10.1051 / \mathrm{e} 3$ sconf/202017404019

[11] V.A. Savinova, E.V. Zhegalova, J.V. Semernina, A.S. Kozlova, "Problems of the development of the digital economy at the regional level", Advances in Intelligent Systems and Computing, 2020, vol. 908, pp. 260-268.

[12] V.L. Abashkin, G.I. Abdrakhmanova, S.V. Bredikhin, "Rating of Innovative Development of the Constituent Entities of the Russian Federation. Issue 7", In Ed. by L.M. Gokhberg, Moscow: NRU HSE, 2021. 274 p. (In Russ.).

[13] G.I. Abdrakhmanova, K.B. Bykhovsky, N.N. Veselitskaya, K.O. Vishnevsky, L.M. Gokhberg, "Digital transformation of industries: starting conditions and priorities", in Proceedings of the XXII Apr. Int. Scientific Conf. on the Problems of Economic and Social Development, In Ed. by L.M. Gokhberg, P.B. Rudnik, K.O. Vishnevsky, T.S. Zinina, Moscow: Publisher House of the Higher School of Economics, 2021. 239 p. (In Russ.).

[14] "Digital Technologies in Industry and IT Industry". Official website of the Institute for Statistical Studies and Economics of Knowledge, 2021. (In Russ.). Retrieved from https://issek.hse.ru/about

[15] N.S. Kulyasov, O.T. Shipkova, A.E. Zavialov, G.D. Charyyarova, "Directions of development of digitalization of the oil industry in the Russian Federation", IOP Conference Series: Materials Science and Engineering, Krasnoyarsk, Krasnoyarsk: Institute of Physics and IOP Publishing Limited, 2020. (In Russ.). DOI: 10.1088/1757-899X/919/6/062032

[16] "Digital Activity of Manufacturing Enterprises in 2019”, Moscow: NRU HSE, 2020, 16 p. (In Russ.).

[17] "Digitalization of Manufacturing in 2020: Vectors of Digital Evolution in the COVID-19 Pandemic", Moscow: NRU HSE, 2021. 19 p. (In Russ.).

[18] "Top 15 Digital Technologies in Industry", Official website of the Institute for Statistical Studies and Economics of Knowledge, 2021. (In Russ.). Retrieved from https://issek.hse.ru/news/494926896.htm 